\title{
A modified version of the mental health literacy scale (MHLS) in Iranian people
}

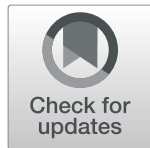

Mahbobeh Nejatian ${ }^{1}$, Hadi Tehrani ${ }^{2}$, Vahideh Momeniyan $^{3}$ and Alireza Jafari ${ }^{4 *}$

\begin{abstract}
Background: The risk rate for the lifetime prevalence of any mental disorder is calculated as 50\%, and the prevalence of mental disorders has an increasing trend. So, this study aimed to evaluate the Mental Health Literacy Scale (MHLS) among Iranian people.

Methods: This cross-sectional study was conducted with a multi-stage sampling method with 1273 people in the general population. After searching and reviewing various sources, the research team decided to use the questionnaire of MHLS with 35 items and six attributes that were measured and developed by O'Connor et al. The face, content, and construct validity (Confirmatory factor analysis) were used for validation of MHLS. McDonald's omega coefficient and Cronbach's alpha coefficient were used to calculate the reliability of MHLS. Confirmatory factor analysis was performed using AMOS software Version 24.

Results: In the CFA test, the six items were deleted. The final modified version of the MHLS included a total of 29 items with six attributes consisted of (a) knowledge of where to seek information (4 items), (b) ability to recognize disorders (8 items), (c) knowledge of self-treatment (2 items), (d) knowledge of risk factors and causes (2 items), (e) attitudes that promote recognition or appropriate help-seeking behavior (10 items), and (f) knowledge of professional help available ( 3 items). Based on the results of reliability, McDonald's omega coefficient and Cronbach's alpha coefficient for all attributes of MHLS were 0.797 and 0.789 , respectively.
\end{abstract}

Conclusion: Due to the lack of appropriate instruments for measuring mental health literacy in the Iranian population, the modified version of MHLS with 29 items and six attributes can be considered as a valid and reliable instrument for this purpose.

Keywords: Mental health literacy, Validity, Reliability, Psychometric, Confirmatory factor analysis, Measures, Public population, Persian, MHLS

\section{Background}

World Health Organization (WHO) reported that 8\% (586 million) of the global population suffer from mental disorders [1]. The results of a study performed in China showed that the prevalence rate of severe mental illness in 1-month and lifetime is 9.35 and $10.10 \%$, respectively [2]. Moreover, based on the results of a meta-analysis

\footnotetext{
* Correspondence: Jafari.ar94@gmail.com

${ }^{4}$ Department of Health Education and Health Promotion, Student Research Committee, Mashhad University of Medical Sciences, Mashhad, Iran

Full list of author information is available at the end of the article
}

conducted in Iran, the prevalence rate of psychiatric disorders was reported as $31.03 \%$ [3].

The frequency of mental disorders among the general population means that many people could directly face a mental health problem in their families, but most of them do not have enough knowledge and skills to assist them [4]. Generally, mental disorders of the individuals can cause shorter lifetime [5]. Mental health literacy (MHL) is considered as a significant predictor of favorable health outcomes [6]. The term of MHL was firstly used in 1997 to describe knowledge and beliefs related to mental disorders that help in diagnosing, managing,

(c) The Author(s). 2021 Open Access This article is licensed under a Creative Commons Attribution 4.0 International License, which permits use, sharing, adaptation, distribution and reproduction in any medium or format, as long as you give appropriate credit to the original author(s) and the source, provide a link to the Creative Commons licence, and indicate if changes were made. The images or other third party material in this article are included in the article's Creative Commons licence, unless indicated otherwise in a credit line to the material. If material is not included in the article's Creative Commons licence and your intended use is not permitted by statutory regulation or exceeds the permitted use, you will need to obtain permission directly from the copyright holder. To view a copy of this licence, visit http://creativecommons.org/licenses/by/4.0/ The Creative Commons Public Domain Dedication waiver (http://creativecommons.org/publicdomain/zero/1.0/) applies to the data made available in this article, unless otherwise stated in a credit line to the data. 
and preventing them. The increased general knowledge, as a prerequisite for early diagnosis and intervention in mental disorders, is required on the concept of mental health and its related disorders $[4,7,8]$.

MHL refers to "focusing on knowledge and strategies to obtain and maintain a good mental health state, knowledge on mental disorders and related treatments, and strategies to decrease stigma and enhance helpseeking efficacy" [6]. Up to now, the studies on mental health have shown that many people have a poor MHL because they have no idea about psychological problems and have negative attitudes about their treatment or effectiveness of the treatments. However, having a high MHL also has several advantages such as prevention from the disease, early diagnosis of symptoms, and performing the necessary interventions to reduce symptoms of mental disorder [4]. The results show that if people have positive attitudes on help-seeking and perceive need for treatment significantly and independently, the use of psychotherapy can be predicted over time by them [9].

The results of a systematic study in Iran showed that $32 \%$ of women had not an adequate level of health literacy. Also, the level of health literacy was low in women with chronic diseases [10]. The results of another systematic study showed that the health literacy status of the Iranian people was inadequate and borderline [11]. The results of a study on Iranian medical sciences students showed that $64.4 \%$ of people were unable to recognize the mental disorder, and 36\% did not know where to help-seeking about mental disorders [12]. Another study conducted in Iran showed that depression literacy was low, and $48.5 \%$ of participants cannot recognize the mental disorder, and $47.15 \%$ didn't intend to seek help ([13]. The results of another study on the general population in Iran showed that mental health literacy status is not sufficient [14].

Given the increasing prevalence of mental disorders and the important role of mental health literacy in reducing these disorders, a suitable tool is needed to measure the level of mental health literacy in the community. However, up to the time of performing this study, no valid and reliable instrument was provided for measuring MHL in Iranian people. Accordingly, all available instruments in Iran could just measure general health literacy and could not specifically measure MHL. After searching and reviewing various sources, the research team decided to use the questionnaire of MHLS with 35 items and six attributes developed by O'Connor et al. [15]. MHL includes six attributes includes of the ability to recognize specific disorders, knowledge of professional help available, knowing how to seek mental health information, knowledge of self-treatments, knowledge of risk factors and causes, and attitudes that promote recognition and appropriate help-seeking [16]. The availability of a valid tool can help people diagnose mental disorders in the early stages, and seek available treatment. Therefore, this study aimed to evaluate the MHLS in the general population of Gonabad, Iran.

\section{Methods}

This cross-sectional study was conducted to evaluate the validity and reliability of the Iranian version of the MHLS with 1273 individuals of the general population in Gonabad, Iran in 2019.

\section{Sample size and sampling method}

The sample size with the $0.95 \%$ confidence level, proportion 0.48 the accuracy of 0.03 , and Considering $20 \%$ of sample loss, was estimated at 1330 subjects [13]. In this study, 1330 questionnaires were distributed among the participants. Finally, 1273 questionnaires were returned, of which 57 questionnaires were excluded from the study due to incomplete information. The final analysis was performed on 1273 participants, and the response rate in this study was $96 \%$.

In this study, the participants were selected by multistage sampling. Initially, the number of community health centers and the population of each one of them were determined. In the next step, these centers were stratified as follows: each center was considered as one category and the sample size was determined due to the population of each category. Finally, the participants were randomly selected from each center. In the present study, the interviewers completed the questionnaire for illiterate participants. The inclusion criteria were the followings: age over 18 years old, having no physical or mental disorder, signing the written informed consent to participate in the study, and being resident of Gonabad city.

\section{Instruments}

Data collection tools included a demographic section and Mental Health Literacy Scale (MHLS).

\section{Demographic questionnaire}

This questionnaire includes questions on gender, age, occupation, level of education, marital status, etc.

\section{MHLS}

This questionnaire was the development and evaluation by O'Connor et al. in 2015 [15].

The MHLS is a single-factor measure. This questionnaire has 35 questions and six attributes. While there are items related to the relevant attributes, they are intended to be considered together. Also, these attributes were review and adapted with studies of Jorm [17], Griffiths, et al., [18], and Jorm, et al. [16]. 
A. Ability to recognize disorders: This attribute consists of eight questions that were measured using a 4-point Likert scale (very unlikely, unlikely, likely, very likely). This attribute refers to "the ability to correctly identify features of a disorder, a specific disorder, or category of disorders".

B. Knowledge of risk factors and causes: This attribute was measured with two questions and using a 4-point Likert scale (very unlikely, unlikely, likely, very likely). This attribute refers to "knowledge of environmental, social, familial or biological factors that increase the risk of developing a mental illness".

C. Knowledge of self-treatment: was measured This attribute consists of two questions that were measured using a 4-point Likert scale (very unhelpful, unhelpful, helpful, very helpful). This attribute refers to "knowledge of typical treatments recommended by mental health professionals and activities that an individual can conduct".

D. Knowledge of professional help available: This attribute was measured with three questions and using a 4-point Likert scale (very unlikely, unlikely, likely, very likely). This attribute refers to "knowledge of mental health professionals and the services they provide".

E. Knowledge of where to seek information: This attribute consists of four questions that were measured using a 5- option Likert scale (strongly disagree, disagree, neither agree nor disagree, agree, strongly agree). This attribute refers to "knowledge of where to access information and capacity to do so".

F. Attitudes that promote recognition or appropriate help-seeking behavior: This attribute consists of sixteen questions and were measured using a 5-option Likert scale [(strongly disagree, disagree, neither agree nor disagree, agree, strongly agree) or (definitely willing, probably willing, neither willing nor unwilling, probably unwilling, definitely unwilling). This attribute refers to "attitudes that impact on the recognition of disorders and willingness to engage in help-seeking behavior".

In this questionnaire, the lowest score is 35 , the highest score is 160 , and higher scores indicate a better MHL status. The validity and reliability of this questionnaire were evaluated in the O'Connor study. The internal consistency of this scale was measured by Cronbach's alpha (Cronbach's alpha $=0.873)[15]$.

\section{Translation and cultural adaptation}

In this research, we used the forward-backward method to do the translation and cultural adaptation [19]. At first, the original English version of the questionnaire was translated into the Persian language by two experts separately. Afterward, the two translated versions were reviewed and a single Persian version of the questionnaire was then prepared. Subsequently, one expert in English language who was not familiar with the specialized English text of psychology back-translated the text into English. Thereafter, the English text of the backward-translation version was adapted with the original English version of the questionnaire. Finally, the English translation was re-translated into Persian language by three psychology specialists who were expert in English language. Moreover, the validity and reliability of the questionnaire were evaluated.

\section{Validation}

Given the reason that the standard questionnaire has been used and translated in this study, quantitative content and face validities were not required to be measured [20]. Furthermore, in this study, the validity of the questionnaire was assessed by qualitative face and content validities.

\section{Validity (qualitative of face and content validity)}

To assess the face validity, face-to-face interviews were conducted with some of the participants $(n=8)$ to find out any difficulty in understanding the words and phrases, the appropriateness and relevance of the items, the likelihood of ambiguity and misunderstandings, or any failure in conceptualization. In case of any problem, the participants' comments were applied to the questionnaire.

To assess the content validity, the questionnaire was provided to 10 specialists (panel of experts in the fields of psychology, health literacy, and health education and promotion) for the purpose of evaluating grammar, use of appropriate words, the importance of items, the correct placement of items, and the time for completing the designed instrument in the present study. After collecting the expert evaluations' results, necessary changes were made in consultation with the members of the research team.

\section{Confirmatory factor analysis (CFA)}

CFA was used to evaluate the construct validity. Before CFA, the obtained data were analyzed using Mahalanobis statistics for the outliers. Subsequently, the normality of the data was evaluated using skewness and kurtosis. CFA was then performed using AMOS version 24 software. Subsequently, the items with weak internal consistency were removed from the questionnaire to obtain an acceptable model. Based on the results, to find an acceptable final model, those questions with a factor loading less than 0.3 were deleted [21]. 
The assessment of the model was conducted with using the following fit indices: Chi-square ratio to the degree of freedom $(\times 2 / \mathrm{df})$; root means square residual (RMR); root means the square error of approximation (RMSEA); goodness of fit index (GFI); adjusted goodness of fit index (AGFI); parsimonious normed fit index (PNFI); parsimony comparative fit index (PCFI); incremental fit index (IFI); parsimony goodness-of-fit index (PGFI); comparative fit index (CFI); and parsimonious normed fit index (PNFI) [22-24]. The model was acceptable if the $(\times 2 / \mathrm{df})<5$, RMSEA and RMR $\leq 0.08$, PCFI, PNFI and PGFI $>0.5$, AGFI $>0.8$, and other indices of IFI, GFI, CFI > 0.9 [22-25].

\section{Reliability assessment}

McDonald's omega coefficient and Cronbach's alpha coefficient were used to assess the internal consistency of the questionnaire and each of the attributes separately. The JASP (Version 0.11.1) software and $\mathrm{SPSS}_{\mathrm{v} 22}$ were used to calculate the amount of McDonald's omega coefficient and Cronbach's alpha coefficient, respectively. McDonald's omega coefficient provides a more accurate approximation than Cronbach's alpha coefficient [26]. Based on the results, when developing a new measure, the value of the reliability coefficient above 0.70 is routinely considered acceptable [27]. Based on the results of the Wallston study, Cronbach's alpha coefficient of 0.6 was considered as the minimum acceptance criterion for the internal reliability of the questionnaire [28]. The lower values of McDonald's omega coefficient and Cronbach's alpha coefficient be related to their low number of items is some attributes [27]. A summary of the modifying of MHLS is presented in Fig. 1.

\section{Results}

The mean (standard deviation) age of the participants in this study was $31.17(10.13)$, and $58 \%(n=732)$ of participants were female, and $68.8 \%(n=864)$ were married. Most of them had an associate/bachelor's degree (57.9\%) and a high school diploma (29.9\%). In this study, $79.5 \%$ $(n=936)$ of the participants were residents in the city, and most of them were self-employed (38.4\%) (Table 1). The mean (SD) of the total MHLS was 97.99 (11.47).

\section{Validity (qualitative of face and content validity)}

No question was omitted during the translation and cultural adaptation processes because the subject's statements in the original questionnaire were similar to the culture of the Iranian population. During the processes of face and content validities' assessment, the questionnaire was given to 10 specialists (panel of experts in the fields of psychology, health literacy, and health education and promotion). As a result, seven and nine items that had difficulties in understanding of the words and

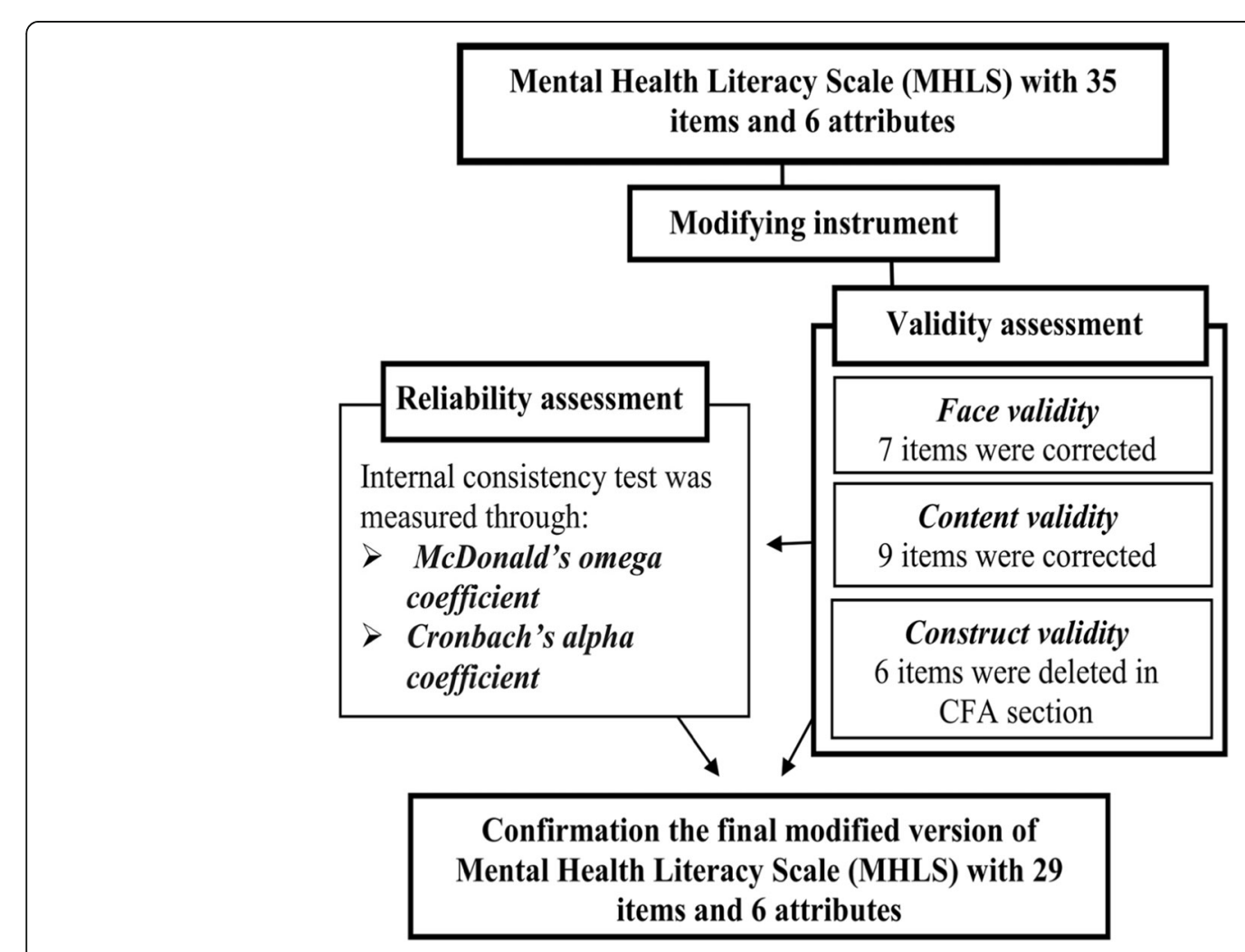

Fig. 1 A summary of the modifying of MHLS 
Table 1 Frequency distribution of demographic characteristics $(n=1273)$

\begin{tabular}{llll}
\hline Variables & & N & $\%$ \\
\hline Gender & Male & 531 & 42 \\
Marital status & Female & 732 & 58 \\
& Marriage & 864 & 68.8 \\
& Single & 391 & 31.2 \\
Education level & Elementary & 38 & 3.2 \\
& Diploma & 366 & 29.9 \\
\multirow{4}{*}{ Residence } & Associate or Bachelor's Degree & 708 & 57.9 \\
& Master's degree or High degree & 109 & 9 \\
Occupation & Urban & 936 & 79.5 \\
& Rural & 242 & 20.5 \\
& Housewife & 211 & 17.4 \\
& Employed & 363 & 30 \\
& Self-employed & 464 & 38.4 \\
& labor & 101 & 8.3 \\
& Unemployed & 71 & 5.9 \\
\hline
\end{tabular}

grammatical problem, were corrected in face and content validities, respectively (Fig. 1).

\section{Confirmatory factor analysis (CFA)}

The results of the CFA analysis showed that the CR value of each question was above 1.96 and the significance level of all questions was less than 0. 001. The goodness of fit for these six attributes model was acceptable: $\mathrm{X} 2 / \mathrm{df}=4.672, \mathrm{RMR}=0.047, \mathrm{RMSEA}=0.054, \mathrm{PCFI}=$ 0.772 , PGFI $=0.749, \quad$ PNFI $=0.748, \quad$ AGFI $=0.893, \quad$ GFI $=$ 0.913, CFI $=0.901$, and IFI $=0.901$ (Table 2). In the CFA stage, to obtain an acceptable final model, six questions with a factor loading less than 0.3 were deleted (Table 3 ).
The factor loading value of each question is visible in Table 3 and Fig. 2.

The final version of the MHLS included a total of 29 items, which consisted knowledge of where to seek information (4 items), knowledge of self-treatment (2 items), ability to recognize disorders (8 items), attitudes that promote recognition or appropriate help-seeking behavior (10 items), knowledge of risk factors and causes (2 items), and knowledge of professional help available (3 items) (Table 4). Details attributes of MHLS are available in Table 4.

\section{Reliability}

McDonald's omega coefficient for all questions of MHLS, MHLS attributes includes the ability to recognize disorders, knowledge of where to seek information, knowledge of risk factors, knowledge of self-treatment, knowledge of professional help available, attitudes that promote recognition or appropriate help-seeking behavior, were 0.797 , $0.734,0.652,0.601,0.602,0.643$, and 0.874 respectively (Table 4). Cronbach's alpha coefficient for all questions of MHLS, MHLS attributes includes the ability to recognize disorders, knowledge of where to seek information, knowledge of risk factors, knowledge of self-treatment, knowledge of professional help available, attitudes that promote recognition or appropriate help-seeking behavior, were $0.789,0.700,0.630,0.600,0.600,0.640$, and 0.800 , respectively (Table 4).

\section{Discussion}

This study aimed to evaluate the Mental Health Literacy Scale (MHLS) among Iranian people. It is noteworthy that there is no specified instrument for evaluating MHL in Iran up to now, and besides, no study was conducted on psychometrically the MHLS. One of the features of

Table 2 The model fit indicators of MHLS

\begin{tabular}{lll}
\hline Goodness of fit indices & Confirmatory factor analysis & Acceptable value \\
\hline $\mathbf{X}^{2}$ & 1667.778 & - \\
$\mathbf{d f}$ & 357 & - \\
$\mathbf{X}$ /df & 4.672 & $<0.5$ \\
$\boldsymbol{p}$-value & 0.001 & $>>05$ \\
CFI & 0.901 & $>0.9$ \\
IFI & 0.901 & $>0.9$ \\
GFI & 0.913 & $>0.9$ \\
AGFI & 0.893 & $>0.8$ \\
RMSEA & 0.054 & $<0.08$ \\
RMR & 0.047 & $<0.08$ \\
PNFI & 0.748 & $>0.5$ \\
PCFI & 0.772 & $>0.5$ \\
PGFI & 0.749 & $>0.5$ \\
\hline
\end{tabular}


Table 3 Factor loadings of the MHLS in the CFA stage

Ability to recognize disorders (AR1-AR 8)

Knowledge of risk factors and causes (RF1,RF2)

Knowledge of self-treatment (ST1,ST2)

Knowledge of the professional help available (PH1PH3)

Knowledge of where to seek information (SI1-SI4)

\section{Items}

Factor

loadings

1. If someone gets very anxious and nervous in one or more situations in

0.468

front of other people, for example at a party or when he has to do

something (such as giving a speech in a meeting), in which they were afraid of others or feel ashamed, how much do you think that person has Social Phobia.

2. If a person is very worried about several events and activities, where this level of concern was not warranted, cannot control this worry, and had physical symptoms (such as muscle cramps and feeling tired), how much do you think this person has a Generalized Anxiety Disorder.

3. If a person had a low mood for two or more weeks, not interested in normal and daily activities, and feels changes in his appetite and sleep, how much do you think this person has Major Depressive Disorder.

4. To what extent do you think Personality Disorders can be classified as a mental illness.

5. How likely do you think Dysthymia is a disorder.

6. To what extent do you think being anxious in situations and places where 0.575 escaping is difficult or embarrassing can be diagnosed as a "Agoraphobia".

7. How likely do you think the diagnosis of Bipolar Disorder includes experiencing a period of happy mood and periods of sad mood (depression) by someone.

8. To what extent do you think physical and psychological tolerance for drugs (need for more substances to maintain its effect on the body) may be identified as drug dependence and addiction.

1. In general, to what extent do you think women in Iran may be more experience any mental illness than men.

2. In general, to what extent do you think men in Iran may be more experience anxiety disorders more than women.

1. If someone has difficulty managing their emotions (for example, becoming very anxious or depressed), how much do you think improving their sleep quality can be beneficial to them?

2. If someone has difficulty managing their emotions (for example, becoming very anxious or depressed), how much do you think avoiding all activities or situations that made them feel anxious can be beneficial to them.

1. In your opinion, it is likely that that Cognitive Behavior Therapy is a therapy based on challenging negative thoughts and increasing helpful behaviors.

2. Mental health professionals are bound by confidentiality; however, there are certain conditions under which this does not apply.

To what extent do you think it is likely that the following is a condition that would allow a mental health professional to break confidentiality: -If you are at risk of harming yourself or others, how likely do you think a Mental health professional will reveal your secrets to others?

3. Mental health professionals are bound by confidentiality; however, there are certain conditions under which this does not apply.

To what extent do you think it is likely that the following is a condition that would allow a mental health professional to break confidentiality: -If your problem does not a serious threat to your life and Mental health professionals want to get assist others to better support you, how likely do you think a Mental health professional will tell your secrets to others?

1. I'm sure I know where to look for information about mental disorders.

2. I'm sure I can use computers and telephones to seek information about mental disorders.

3. I'm sure attending face to face meeting to seek information about mental disorders (e.g., seeing the general practitioner, psychologist).

4. I am confident that I have access to resources such as the Internet, general practitioner, friends, etc. to seek information about mental disorders. 
Table 3 Factor loadings of the MHLS in the CFA stage (Continued)

\begin{tabular}{|c|c|c|}
\hline Attributes & Items & $\begin{array}{l}\text { Factor } \\
\text { loadings }\end{array}$ \\
\hline \multirow{16}{*}{$\begin{array}{l}\text { Attitudes that promote the recognition or } \\
\text { appropriate help-seeking behavior(A1-A10) }\end{array}$} & 1. People with mental disorders are dangerous. & 0.355 \\
\hline & $\begin{array}{l}\text { 2. It is best to avoid people with a mental disorder so that you don't } \\
\text { develop this problem }\end{array}$ & 0.344 \\
\hline & 3. If I have a mental disorder, I do not like to tell anyone. & 0.310 \\
\hline & $\begin{array}{l}\text { 4. How much do you want to move next door to someone with a mental } \\
\text { illness? }\end{array}$ & 0.807 \\
\hline & $\begin{array}{l}\text { 5. How much do you want to spend the night with someone who has a } \\
\text { mental disorder? }\end{array}$ & 0.850 \\
\hline & $\begin{array}{l}\text { 6. How much do you want to be friends with someone who has a mental } \\
\text { disorder? }\end{array}$ & 0.887 \\
\hline & $\begin{array}{l}\text { 7. How much do you want to start working with someone who has a } \\
\text { mental disorder? }\end{array}$ & 0.826 \\
\hline & $\begin{array}{l}\text { 8. How much do you want to have someone with a mental illness marry } \\
\text { into your family? }\end{array}$ & 0.555 \\
\hline & $\begin{array}{l}\text { 9. How much do you want to vote for a politician who suffering from a } \\
\text { mental illness? }\end{array}$ & 0.410 \\
\hline & 10. How much do you want to employ someone with a mental illness? & 0.613 \\
\hline & $\triangleright$ People with a mental disorder could stop their behaviors if they wanted. & Deleted \\
\hline & $\triangleright$ A mental disorder is a sign of personality weakness. & Deleted \\
\hline & $\triangleright$ A mental disorder is not a real medical disease. & Deleted \\
\hline & $\begin{array}{l}>\text { If I have a mental disorder, I do not like to seek help from a mental } \\
\text { health professional (e.g., psychologist/psychiatrist). }\end{array}$ & Deleted \\
\hline & $\begin{array}{l}>\text { I believe that the treatment of mental disorders by a mental health } \\
\text { professional (e.g., psychologist/psychiatrist) is ineffectiveness. }\end{array}$ & Deleted \\
\hline & $\begin{array}{l}\triangleright \text { Refer to a psychologist means that you do not have enough power to } \\
\text { manage and solve your problem. }\end{array}$ & Deleted \\
\hline
\end{tabular}

the instrument proposed in this study is measuring different aspects of MHL with a short time and with selfadministration. In the present study, this instrument was completed by most of the participants with no problem in a short time. Therefore, this instrument seems to be useful for measuring the MHL of different age groups in society. Accordingly, this tool can be used to measure MHL, to identify individuals with a low level of literacy in any attribute and design, and to implement intervention programs for them.

In the present study, this 35 items questionnaire was evaluated and modified. After evaluation of the questionnaire, six questions were omitted, and the modified version of MHLS with 29 items and six attributes was approved. In the present study for assessing the reliability of the instrument, McDonald's omega coefficient, and Cronbach's alpha coefficient were used and calculated 0.797 and 0.789 , respectively. McDonald's omega coefficient similar to Cronbach's Alpha, but the omega coefficient provides a more accurate approximation of a scale's reliability, and that the omega coefficient is almost always higher than Cronbach's alpha coefficient [26]. Based on the results of many previous study,
McDonald's omega coefficient is a more sensible index of internal consistency compared to Cronbach's alpha and other alternatives [26, 29, 30]. Based on these results, when developing a new measure, the value of the reliability coefficient above 0.70 is routinely considered as acceptable [27].

In a study by Noroozi, the Cronbach's alpha for total attributes of MHLS was 0.74 [31]. Moreover, in a study conducted by O'Connor, the MHLS was designed based on some other questionnaires in this field. In this regard, the 55-item questionnaire was evaluated, in which the MHLS with 35-item and six attributes were finally confirmed after psychometric evaluation of the questionnaire. Accordingly, Cronbach's alpha of 0.879 and testretest reliability of 0.797 were reported [15].

In the CFA stage of the present study, the six items were deleted. The final version of the MHLS was approved with 29 items and included six attributes of ability to recognize disorders (8 items), knowledge of where to seek information (4 items), knowledge of risk factors and causes ( 2 items), knowledge of self-treatment (2 items), knowledge of professional help available (3 items), and attitudes that promote recognition or 


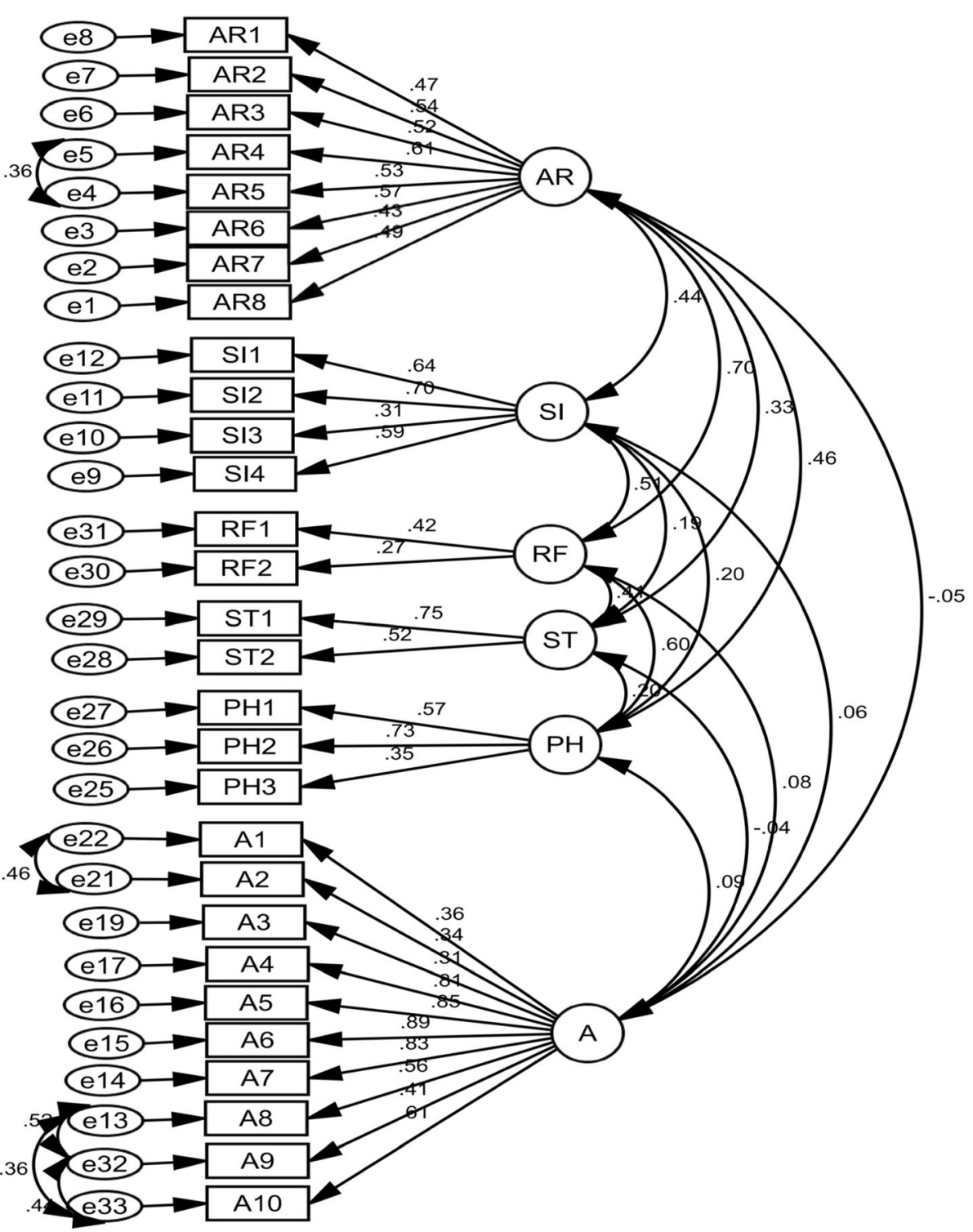

Fig. 2 Standardized parameter estimates for the factor structure of the MHLS

Table 4 Descriptive statistics of the MHLS and its attributes

\begin{tabular}{|c|c|c|c|c|c|c|}
\hline Attributes & Item & Mean & SD & Range & $\begin{array}{l}\text { Cronbach's } \\
\text { alpha }\end{array}$ & $\begin{array}{l}\text { McDonald's } \\
\text { omega }\end{array}$ \\
\hline Ability to recognise disorders (AR) & 8 & 23.81 & 3.52 & $8-32$ & 0.700 & 0.734 \\
\hline Knowledge of where to seek information (SI) & 4 & 13.65 & 2.71 & $4-20$ & 0.630 & 0.652 \\
\hline Knowledge of risk factors (RF) & 2 & 5.39 & 1.07 & $2-8$ & 0.600 & 0.601 \\
\hline Knowledge of self-treatment (ST) & 2 & 5.15 & 0.84 & $2-8$ & 0.600 & 0.602 \\
\hline Knowledge of professional help available (PH) & 3 & 8.43 & 1.15 & $3-12$ & 0.640 & 0.643 \\
\hline $\begin{array}{l}\text { Attitudes that promote recognition or appropriate help seeking } \\
\text { behaviour(A) }\end{array}$ & 10 & 36.58 & 5.30 & $10-50$ & 0.800 & 0.874 \\
\hline The final modified version of MHLS (All attributes) & 29 & 93.03 & 8.16 & $\begin{array}{l}29- \\
130\end{array}$ & 0.789 & 0.797 \\
\hline
\end{tabular}


appropriate help-seeking behavior (10 items). Jung conducted a study aimed to developing and assessing the reliability of an instrument used for evaluating MHL. Correspondingly, the results of the exploratory factor analysis discovered three factors for the 26-item questionnaire. Moreover, the results of CFA showed that the proposed model has a good fit in the stage of CFA. Also, Cronbach's alpha amounts were reported as $0.76,0.77$, and 0.84 for the first factor (knowledge-oriented MHL), the second factor (Beliefs-oriented MHL), and the third factor (resource-oriented MHL), respectively [32]. The results of a systematic review that examined the tools available in the field of the evaluation of MHL, showed that the MHLS used in the present study is an acceptable tool for evaluating MHL in individuals [33].

The first attribute of this instrument was "the ability to recognize disorders". This attribute was confirmed by eight items, Omega 0.734, alpha 0.700 , and factor loading 0.433 to 0.615 . Finding the appropriate tools for early diagnosis of various types of mental disorders is important. The results of a study conducted by Jorm in Australia showed that people who had a better ability in recognizing depression and schizophrenia also were more likely to receive a wide range of interventions including assistance from mental health professionals, psychotherapy, medications, and psychiatric admissions [34].

The second attribute of this instrument was "knowledge of where to seek information". This attribute was confirmed by four items, Omega 0.652 , alpha 0.630 , and factor loading 0.639 to 0.699 . The results of a study performed in China have also indicated that people have great intentions to seek mental health services. However, they have low levels of knowledge on help sources and no knowledge about where to seek potential help sources [35]. Also, the results of a recent systematic review study have shown the improved knowledge on mental disorders/mental health, where to seek help and treatment, the improved the mental health outcomes, and the increased use of mental health services by people [36].

The third attribute of this instrument was "knowledge of risk factors". This attribute was confirmed by two items, Omega 0.601, alpha 0.600 , and factor loading 0.270 to 0.422 . Undoubtedly, one of the less wellregarded aspects of MHL is prevention. We have more knowledge about the risk factors for other diseases compared to the risk factors of mental disorders, and people should also have access to appropriate tools to identify modifiable risk factors for mental disorders [37]. It was indicated that people who have access to the appropriate tools to diagnose risk factors can better manage their preventive behaviors [38].

The fourth attribute of this instrument was "knowledge of self-treatment". This attribute was confirmed by two items, Omega 0.602, alpha 0.600 , and factor loading 0.516 to 0.752 . The ability to diagnose a mental disorder is useful, but the individual must also have knowledge on the available evidence-based treatments [37]. The results of the Thompson's study in Australia showed that the most important reason for psychiatric patients to delay treatment is the lack of knowledge on available treatments [39].

The fifth attribute of this instrument was "knowledge of professional help available". This attribute was confirmed by three items, Omega 0.643, alpha 0.640, and factor loading 0.354 to 0.731 . Another important attribute of MHL is knowledge about professional help available in the community for the treatment of mental disorders [39]. Based on the results, most of the people with a mental disorder receive no treatment from health care service because they do not know how to access an available treatment [40].

The sixth attribute of this instrument was "attitudes that promote recognition or appropriate help-seeking behavior". This attribute was confirmed by ten items, Omega 0.874 , alpha 0.800 , and factor loading 0.355 to 0.887 . Knowing the status of individuals' attitudes that promote recognition or appropriate help-seeking behavior, is essential to prevent some manners like labeling. Therefore, an appropriate tool that can examine people's attitudes can be effective on the processes of prevention and treatment of mental disorders. Findings of a study by Reynders showed that people who have more positive attitudes toward help-seeking and experiencing less selfstigma, have fewer psychological problems, which prevent these problems [41].

\section{Strengths and limitations}

One of the limitations of this study was the shorter final modified version of the questionnaire compared to the original version of the questionnaire, which consequently changed the scoring. Since this questionnaire had no level and mental health literacy status was reported as mean (SD), and also given the fact that obtaining a higher score indicates a better mental health literacy status, so it can be justified. One of the strengths of this study was that it was conducted in the general population with different age groups and social classes. The large sample size was another power of this study. Therefore, given the confirmation of the validity of the MHLS in this study and the applicability of this questionnaire to assess the level of MHL in different groups of society, it is recommended to use this questionnaire to assess the MHL of different target groups for educational, clinical, and research purposes. Also, due to the reason that this questionnaire is new, it is recommended 
to evaluate its psychometric in some other studies with various target populations.

\section{Conclusions}

Based on the results of this study, due to a lack of appropriate tools for evaluating MHL in the Iranian population, the modified version of MHLS with 29 items and six attributes is a suitable instrument for assessing MHL in individuals. Due to the shortness and ease of use, this instrument can be used to measure the level of MHL in different groups of society and to identify people with low MHL. Identifying people with insufficient MHL levels enables mental health services to design and implement appropriate mental health intervention programs and prevent the prevalence of mental disorders in the community.

\section{Abbreviations}

MHLS: Mental Health Literacy Scale; MHL: Mental Health Literacy; CFA: Confirmatory factor analysis; YLDs: Years lived with a disability; DALYs: Disability-adjusted life years; AR: Ability to recognize disorders; SI: Knowledge of how to seek information; RF: Knowledge of risk factors; ST: Knowledge of self-treatment; PH: Knowledge of professional help available; A: Attitudes that promote recognition or appropriate help- seeking behavior

\section{Acknowledgments}

We would like to thanks all people who assisted the authors to run this research project. Also, the authors of the study express their sincere gratitude to all authorities of Student Research Committee of Mashhad University of Medical Sciences (Research project code: 971865).

\section{Authors' contributions}

Authors MN, HT, VM and AJ designed the study. MN, HT, VM and AJ participated in the conception of the study. MN and AJ managed and conducted the statistical analyses and interpreted the data. MN, AJ, VM and HT wrote the first draft and MN, HT and AJ revised it to make the final manuscript. All authors have approved the final manuscript.

\section{Funding}

No financial support was received for this study.

\section{Availability of data and materials}

The data sets used and/or analyzed during the current study were available from the corresponding author on reasonable request.

\section{Ethics approval and consent to participate}

This study is based on a research project approved by the Ethics Committee of Mashhad University of Medical Sciences with the ethics code of IR.MUMS.REC.1398.095. Allparticipants signed a written informed consent. All procedures performed in this study were in accordance with the ethical standards of the institutional and/or national research committee and with the 1964 Helsinki declaration and its later amendments or comparable.

\section{Consent for publication}

Not applicable.

\section{Competing interests}

The authors have no conflicts of interest.

\section{Author details}

${ }^{1}$ Social Determinants of Health Research Center, Gonabad University of Medical Sciences, Gonabad, Iran. ${ }^{2}$ Department of Health Education and Health Promotion, Social Determinants of Health Research Center, Mashhad University of Medical Sciences, Mashhad, Iran. ${ }^{3}$ Department of Psychology, Ferdowsi University of Mashhad, Mashhad, Iran. ${ }^{4}$ Department of Health
Education and Health Promotion, Student Research Committee, Mashhad University of Medical Sciences, Mashhad, Iran.

Received: 5 November 2019 Accepted: 13 January 2021

Published online: 23 January 2021

\section{References}

1. Organization WH. Depression and other common mental disorders: global health estimates. In: World Health Organization. 2017.

2. Wang D, Ma J, Tan L, Chen Y, Li X, Tian X, Zhou X, Liu X. Epidemiology of severe mental illness in Hunan province in Central China during 2014-2015: a multistage cross-sectional study. PLoS One. 2017;12(11):e0188312.

3. Taheri Mirghaed M, Abolghasem Gorji H, Panahi S. Prevalence of psychiatric disorders in Iran: a systematic review and meta-analysis. Int J Prev Med. 2020;11:21.

4. Marcus M, Westra H, Group MMR. Mental health literacy in Canadian young adults: results of a national survey. Canadian Journal of Community Mental Health. 2012;31(1):1-15.

5. Hannerz H, Borgå P, Borritz M. Life expectancies for individuals with psychiatric diagnoses. Public Health. 2001;115(5):328-37.

6. Wei Y, McGrath PJ, Hayden J, Kutcher S. Measurement properties of mental health literacy tools measuring help-seeking: a systematic review. J Ment Health. 2017;26(6):543-55.

7. Reavley NJ, Morgan AJ, Jorm AF. Development of scales to assess mental health literacy relating to recognition of and interventions for depression, anxiety disorders and schizophrenia/psychosis. Australian \& New Zealand Journal of Psychiatry. 2014;48(1):61-9.

8. Waldmann T, Staiger T, Oexle N, Rüsch N. Mental health literacy and helpseeking among unemployed people with mental health problems. J Ment Health. 2019:1-7.

9. Bonabi H, Müller M, Ajdacic-Gross V, Eisele J, Rodgers S, Seifritz E, Rössler W, Rüsch N. Mental health literacy, attitudes to help seeking, and perceived need as predictors of mental health service use: a longitudinal study. J Nerv Ment Dis. 2016;204(4):321-4.

10. Khorasani EC, Tavakoly Sany SB, Orooji A, Ferns G, Peyman N. Health literacy in Iranian women: a systematic review and meta-analysis. Iran J Public Health. 2020;49(5):860-74.

11. Dadipoor S, Ramezankhani A, Aghamolaei T, Rakhshani F, Safari-Moradabadi A. Evaluation of health literacy in the Iranian population. Health Scope. 2018;7(3):e62212.

12. Sayarifard A, Ghadirian L, Mohit A, Eftekhar M, Badpa M, Rajabi F. Assessing mental health literacy: what medical sciences students' know about depression. Med J Islam Repub Iran. 2015;29:161.

13. Ghadirian L, Sayarifard A. Depression literacy in urban and suburban residents of Tehran, the Capital of Iran; recognition, help seeking and stigmatizing attitude and the predicting factors. Int J Prev Med. 2019;10.

14. Noroozi A, Khademolhosseini F, Lari H, Tahmasebi R. The mediator role of mental health literacy in the relationship between demographic variables and health-promoting Behaviours. Iranian Journal of Psychiatry and Behavioral Sciences. 2018; In Press.

15. O'Connor M, Casey L. The mental health literacy scale (MHLS): a new scalebased measure of mental health literacy. Psychiatry Res. 2015;229(1-2):511-6.

16. Jorm AF, Korten AE, Jacomb PA, Christensen H, Rodgers B, Pollitt P. "Mental health literacy": a survey of the public's ability to recognise mental disorders and their beliefs about the effectiveness of treatment. Med J Aust. 1997; 166(4):182-6.

17. Jorm AF. Mental health literacy: public knowledge and beliefs about mental disorders. Br J Psychiatry. 2000;177(5):396-401.

18. Griffiths KM, Christensen H, Jorm AF, Evans K, Groves C. Effect of web-based depression literacy and cognitive-behavioural therapy interventions on stigmatising attitudes to depression: randomised controlled trial. The British journal of psychiatry : the journal of mental science. 2004;185:342-9.

19. Organization WH: Process of translation and adaptation of instruments. 2007. In: 2010.

20. Taghizadeh Z, Ebadi A, Montazeri A, Shahvari Z, Tavousi M, Bagherzadeh R. Psychometric properties of health related measures. Part 1: translation, development, and content and face validity. Payesh. 2017;16(3):343-57.

21. Ellis JL. Factor analysis and item analysis. Applying Statistics in Behavioural Research. 2017:11-59. 
22. Henry JW, Stone RW. A structural equation model of end-user satisfaction with a computer-based medical information system. Information Resources Management Journal (IRMJ). 1994;7(3):21-33.

23. Kline R: Details of path analysis. Principles and practice of structural equation modeling. In.: New York: Guilford; 2005.

24. Lomax RG, Schumacker RE: A beginner's guide to structural equation modeling: psychology press; 2004.

25. Schreiber JB, Nora A, Stage FK, Barlow EA, King J. Reporting structural equation modeling and confirmatory factor analysis results: a review. J Educ Res. 2006;99(6):323-38

26. Revelle W, Zinbarg RE. Coefficients alpha, beta, omega, and the glb: comments on Sijtsma. Psychometrika. 2009;74(1):145.

27. Viladrich C, Angulo-Brunet A, Doval E. A journey around alpha and omega to estimate internal consistency reliability. Ann Psychol. 2017;33(3):755-82.

28. Jomeen J, Martin CR. A psychometric evaluation of form C of the multidimensional health locus of control (MHLC-C) scale during early pregnancy. Psychology, health \& medicine. 2005;10(2):202-14.

29. Graham JM. Congeneric and (essentially) tau-equivalent estimates of score reliability: what they are and how to use them. Educ Psychol Meas. 2006; 66(6):930-44.

30. Dunn TJ, Baguley T, Brunsden V. From alpha to omega: a practical solution to the pervasive problem of internal consistency estimation. $\mathrm{Br} J$ Psychol. 2014;105(3):399-412.

31. Noroozi A, Khademolhosseini F, Lari H, Tahmasebi R. The mediator role of mental health literacy in the relationship between demographic variables and health-promoting behaviours. Iranian Journal of Psychiatry and Behavioral Sciences. 2018;12(2):e12603.

32. Jung $\mathrm{H}$, von Sternberg $\mathrm{K}$, Davis $\mathrm{K}$. Expanding a measure of mental health literacy: development and validation of a multicomponent mental health literacy measure. Psychiatry Res. 2016;243:278-86.

33. Wei Y, McGrath PJ, Hayden J, Kutcher S. Measurement properties of tools measuring mental health knowledge: a systematic review. BMC psychiatry. 2016;16(1):297.

34. Jorm AF, Christensen H, Griffiths KM. The public's ability to recognize mental disorders and their beliefs about treatment: changes in Australia over 8 years. The Australian and New Zealand journal of psychiatry. 2006;40(1):3641.

35. Yu Y, Liu ZW, Hu M, Liu HM, Yang JP, Zhou L, Xiao SY. Mental health helpseeking intentions and preferences of rural Chinese adults. PLoS One. 2015; 10(11):e0141889.

36. Wei Y, McGrath PJ, Hayden J, Kutcher S. Mental health literacy measures evaluating knowledge, attitudes and help-seeking: a scoping review. BMC psychiatry. 2015;15:291.

37. Jorm AF. Mental health literacy: empowering the community to take action for better mental health. Am Psychol. 2012;67(3):231.

38. Dev A, Gupta S, Sharma KK, Chadda RK. Awareness of mental disorders among youth in Delhi. Current Medicine Research and Practice. 2017;7(3): 84-9.

39. Thompson A, Hunt C, Issakidis C. Why wait? Reasons for delay and prompts to seek help for mental health problems in an Australian clinical sample. Soc Psychiatry Psychiatr Epidemiol. 2004;39(10):810-7.

40. Henderson C, Evans-Lacko S, Thornicroft G. Mental illness stigma, help seeking, and public health programs. Am J Public Health. 2013;103(5):77780.

41. Reynders A, Kerkhof AJ, Molenberghs G, Van Audenhove C. Attitudes and stigma in relation to help-seeking intentions for psychological problems in low and high suicide rate regions. Soc Psychiatry Psychiatr Epidemiol. 2014; 49(2):231-9.

\section{Publisher's Note}

Springer Nature remains neutral with regard to jurisdictional claims in published maps and institutional affiliations.

Ready to submit your research? Choose BMC and benefit from:

- fast, convenient online submission

- thorough peer review by experienced researchers in your field

- rapid publication on acceptance

- support for research data, including large and complex data types

- gold Open Access which fosters wider collaboration and increased citations

- maximum visibility for your research: over $100 \mathrm{M}$ website views per year

At $\mathrm{BMC}$, research is always in progress.

Learn more biomedcentral.com/submissions 